\title{
Safe surgery: analysis of physicians' adherence to protocols, and its potential impact on patient safety
}

\section{Cirurgia segura: análise da adesão do protocolo por médicos e possível impacto na segurança do paciente}

Pedro Henrique Alves Silva ${ }^{10}$; Murilo Baracat Cortese Conde ${ }^{1}$; Pedro Favero Martinasso ${ }^{1}$; Renan Parise Maltempi ; João César JACON ${ }^{1}$.

\begin{abstract}
A B S T R A C T
Objectives: to identify surgeons' knowledge and compliance rate to the Safe Surgery Protocol, as well as to assess the incidence of surgery-related adverse events, including patients' knowledge about the protocol. Methods: this is a cross-sectional and prospective study. An instrument was developed to collect the socio-graphic characteristics of sixty-eight surgeons and residents, their knowledge and adherence to the safe surgery protocol. Eighty-two patients were assessed regarding their awareness about the surgical procedure. The operating environment was also evaluated. Descriptive statistics and the odds ratio are presented. Results: the surgeons, despite their previous contact with the protocol throughout the graduation period, were poorly compliant with it. Adverse events such as the use of uncalibrated equipments or the presence of foreign bodies in several equipments such as drills and cautery pens were identified. In addition, some of the adverse events were identified and fixed, after patients had already been anesthesized, but before the beginning of the surgical procedure. Patients demonstrated knowledge about the operation they would undergo, but they did not know about its duration, and they were not introduced to the surgical team. Conclusion: there were failures in the dynamics and compliance regarding some phases of the protocol, which may impact the laterality errors and patient safety.
\end{abstract}

Keywords: Patient Safety. Protocols. General Surgery. Orthopedics. Surgery. Plastic.

\section{INTRODUCTION}

D atient safety has been a concern for thousands of years. Hippocrates (460 to $370 \mathrm{BC}$ ), was one of the first to highlight this aspect and the maxim primum non nocere, which means "first, do no harm" has been attributed to him. Whether this was indeed Hippocrates' authorship remains an enigma, but this principle has been taken by many physicians ever since antiquity. It has been known that those who take care of patients should always have the perception that health care is not exempt from failures, in particular those related to the physicians ${ }^{1}$.

In contrast, the current context is marked by pressures related to the high cost of health care, which is associated with technological incorporation, increase in the workload of health professionals, and the aging of the population who present with multiple chronic diseases. Such situation has led health organizations to assess the quality of health care with an emphasis on actions aiming continuous improvement and accountability².

The surgical results have significantly improved, and highly complex surgical procedures have become the routine. On the other hand, technological advances have made the surgical environment more unsafe ${ }^{3}$. Approximately 234 million operations are performed annually worldwide, about seven million patients have severe complications, and one million die during or shortly after surgery. Even the simplest procedures involve dozens of critical steps, with countless opportunities for failure and a high potential for mistakes that might result in injuries to the patients. Thus, some initiatives must be implemented to reduce the risk of surgical related adverse events, highlighting the importance of the correct identification of patients and the surgical site, efficient sterilization of the used material; safe administration of anesthesia; and surgical performance under rigorous techniques ${ }^{5}$.

Surgical complications account for a large proportion of medical deaths and injuries that can

1 - Faculdade de Medicina de Catanduva, Curso de Medicina - Catanduva - SP - Brasil. 
be prevented worldwide. Adverse events have been estimated to affect $3-16 \%$ of all hospitalized patients, and more than half of these events are known to be preventable. Despite the considerable improvement in knowledge about surgical safety, at least half of the adverse events occur during the operation. Assuming a perioperative adverse event rate of $3 \%$ and a mortality rate of $0.5 \%$, worldwide almost 7 million surgical patients will suffer significant complications each year, 1 million of whom will die during or immediately after the operation ${ }^{6}$.

In October of 2004, the WHO created the World Alliance for Patient Safety, which, from 2005 on, has tackled priority topics to be addressed every two years, known as Global Challenges ${ }^{7}$. In 2007-2008, the second global challenge established as safety improvement in the surgical environment (Safe Surgery) as a priority, aiming to increase the standards of quality and safety of surgical care by four crucial actions: prevention of surgical site infections; safe anesthesia; safe surgical teams; and surgical audits. Based on these actions, the Safe Surgery Saves Lives campaign was launched in several countries ${ }^{1}$.

There are at least four underlying challenges to improve surgical safety. First, it has not been recognized as a relevant public health issue, yet. The second problem is that the lack of access to basic surgical care remains a concern in low-income settings. In fact, the simultaneous need for initiatives to improve the safety and reliability of surgical interventions has not been widely recognized. The third underlying problem in ensuring surgical safety is that existing safety practices seem not have been adopted by many countries. Thus, surgical site infection, for example, remains one of the most common causes of surgical complications. The fourth underlying problem for improving surgical safety is its complexity. Even the simplest procedures involve dozens of critical steps, each with chances of failure, and the potential to cause injury to patients ${ }^{6}$.

These factors encompass the various dimensions of patient safety culture that an organization should establish and follow over the years. Furthermore, there is another aspect of the safety culture that is very strong in the healthcare process: the belief that healthcare professionals are infallible and, with that, the adverse events, with or without harm, are still little reported by professionals, because they fear their competence can be questioned.

Therefore, based on the number of adverse events that still occur, even after the introduction of the Safe Surgery Protocol proposed by the ANVISA, our goal is to analyze the compliance and knowledge about the WHO Safe Surgery Protocol by surgeons in two hospitals, in a city in the northwestern of São Paulo state. Therefore, we sought to identify, characterize, and understand noncompliances to the protocol, as well as to identify adverse events related to the surgical procedures, and highlight initiatives that may change this scenario. We also aimed to identify the knowledge and the compliance to the Safe Surgery Protocol by attendings and residents of surgery, as well as the incidence of adverse events related to the procedures.

\section{METHODS}

This is a cross-sectional and prospective study. The study sites were the surgical centers at the Hospital Escola Emílio Carlos and the Hospital Padre Albino, both located in Catanduva-SP. The study population included eighty-two patients, from both sexes, and sixtyeight attending and resident physicians who agreed to participate and signed the Informed Consent Form (ICF).

The data collection took place from March to August 2019. A self-developed instrument based on the Ministry of Health adapted version of the WHO Safe Surgery Protocol was used. The instrument, with 26 questions, was divided into three parts: the first consisted of the sample's sociodemographic identification (teaching and resident surgeons). It included variables such as age, sex, time and place of training, and specialty. The second part consisted of questions aimed to identify the knowledge and compliance of surgeons (attending or residents) to the safe surgery protocol. The third part assessed the patients who underwent the surgical procedure by direct in loco observations, as well as the auditing, regarding safety procedures.

The instrument was validated based on its objectivity, clarity, and specificity. Two surgeons and two nurse specialists in patient safety participated in the process, which also considered the practical applicability of the instrument.

Any surgical specialty procedure was included. 
Patients were excluded if they were unconscious or had mental impairment which would impact their answers. Those who did not consent to participate and did not sign the IC were also excluded.

The results were analyzed using descriptive statistics and odds ratio (OR) with a 95\% confidence interval $(\mathrm{Cl})$.

The research followed the recommendations of the Resolution $N^{\circ} 466 / 12$ of the National Health Council on research involving human beings. The research project was sent to the managers of the participating institutions for final consent, and forwarded to the Ethics and Research Committee of the educational institution where it was authorized, (Committee number 3,238,088).

\section{RESULTS}

Thirty-five residents and thirty-three attendings answered the questionnaire. The average age was thirtysix years (Figure 1), and most of them graduated from FAMECA (33.82\%) and UNOESTE (8.82\%) (Figure 2). The average time since medical graduation was eleven years (Figure 3). Most professionals were orthopedic surgeons or residents in Orthopedics and Traumatology (26.47\%), followed by General Surgery (22.05\%), and Plastic Surgery (16.17\%) (Figure 4).

The majority of the professionals (58.83\%) denied having had any training regarding the safe surgery protocol. However, when asked about previous contact with the protocol during graduation, $51.47 \%$ confirmed the existence of the Safe Surgery Protocol in their medical graduation curriculum. Regarding intraoperative adverse events, $70.58 \%$ of the professionals confirmed having had problems due to uncalibrated equipment. When asked about adverse situations after the patient had already been anesthetized, $26.47 \%$ witnessed the interruption of the procedure due to the lack of equipment, $27.94 \%$ due to lack of materials, $19.11 \%$ due to the lack of workups and $33.82 \%$ due to the lack of assessment/control of preoperative comorbidities. When asked about surgical materials, $44.11 \%$ witnessed inadequate sterilization. When analyzing the surgeons' average training time versus their knowledge about the Safe Surgery Protocol, we identified an OR of 8.23 and a $\mathrm{Cl}$ of 2.37 to 28.6, favoring the younger professionals.
There were 78 patients (sex not specified) included. When checking whether they were asked about allergies, $88.46 \%$ stated that this question had been preoperatively assessed. $93.58 \%$ of the patients were aware of the surgical procedure they would undergo, and $94.87 \%$ were able to inform the surgical site. On the other hand, when questioned about the duration of the procedure, $83.33 \%$ were unable to say how long the it would take, and $76.92 \%$ were unaware of what type of anesthesia they would undergo. Besides, $70.51 \%$ said they had not been introduced to the surgical team (doctor, anesthetist, nurses). $71.79 \%$ of the patients did not have the surgical site (laterality) identified before admission to the operation room, however, immediately before, the surgical site was identified in $70.51 \%$ of them.

When checking the medical records, $67.94 \%$ of the patients were not prescribed antibiotic prophylaxis, as this was not prescribed by the doctor responsible for the operation, and $82.05 \%$ did not have blood bank reservation.

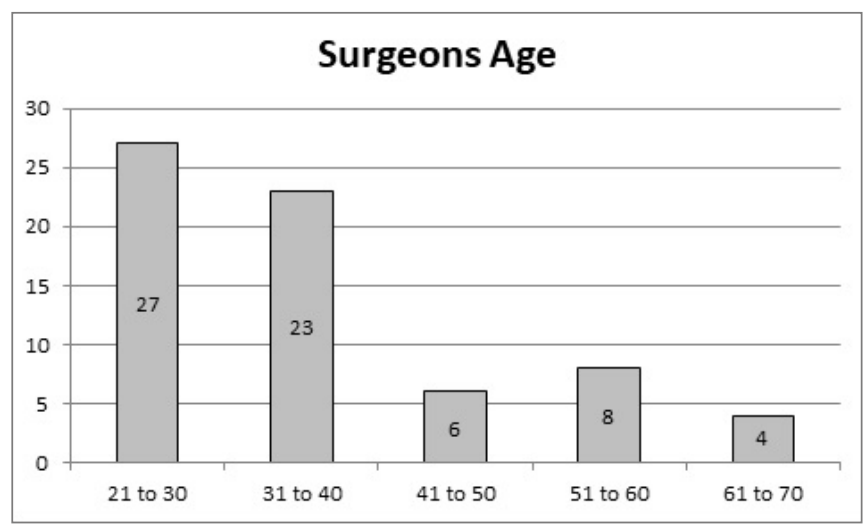

Figure 1. Surgeons age.

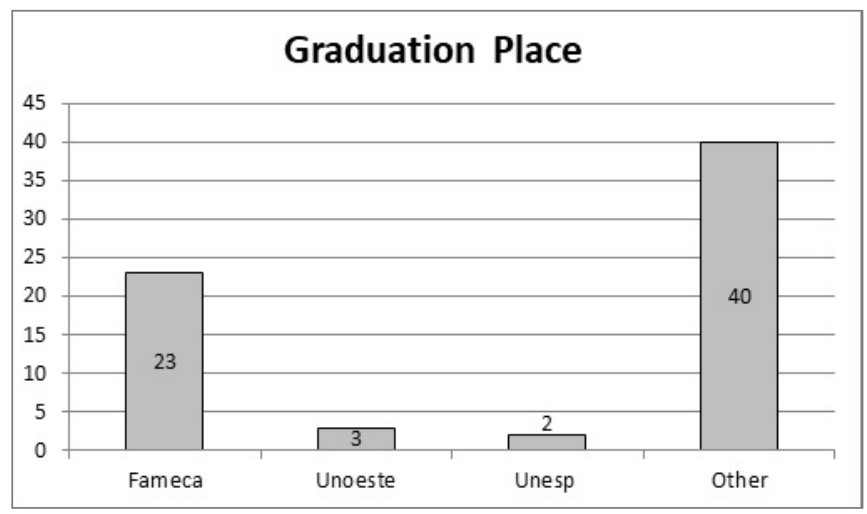

Figure 2. Medical school. 


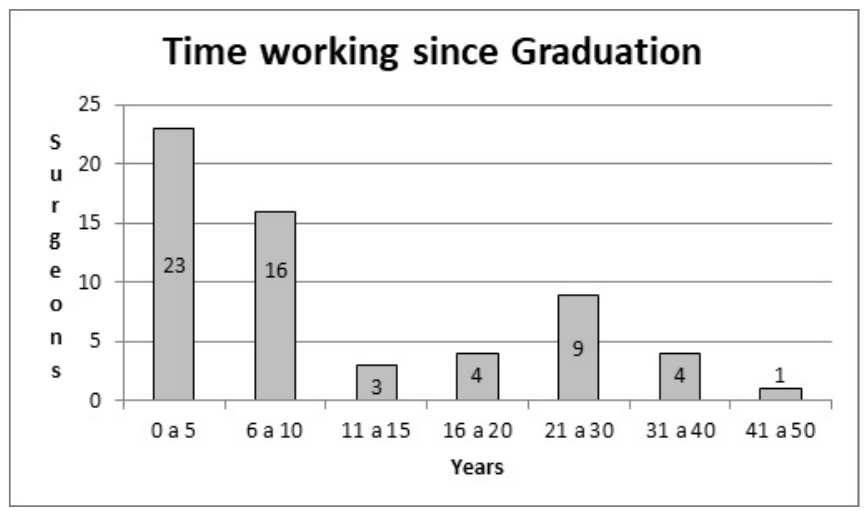

Figure 3. Time since graduation.

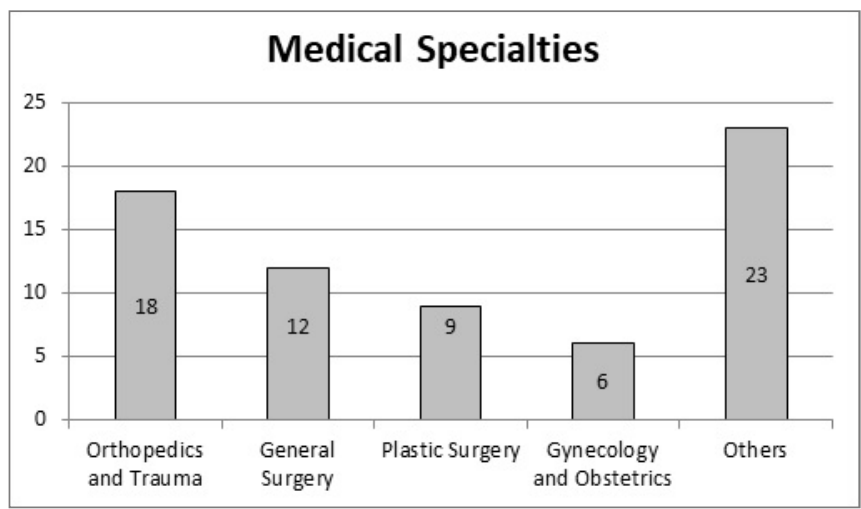

Figure 4. Surgeons specialty.

\section{DISCUSSION}

Our data indicate that most surgeons were graduates from country town institutions in the state of São Paulo, which is in accordance with the Brazilian Medical Demography (2018) Report showing that $70 \%$ of the available medical school places are located in country towns, in the state of São Paulo.

Our results have showed that training time is inversely associated to being acquainted with the safety protocol. This may be related to the National Health Department Ordinance 529, April 2013, whose specific objectives were to "promote the inclusion of Patient Safety topics in the undergraduate and graduate medical education curriculum" 9 . Despite these goals, no guidance how to implement them has been provided. However, the official material regarding Patient Safety, published in 2014, reinforces the importance of including patient safety topics in the medical curriculum, and highlights the need to develop updated material encompassing several information to assist managers, medical professionals, and patients. In addition, it recommends that healthcare institutions develop presential and online training courses $^{10}$

Although most surgeons had had previous contact with the protocol throughout their graduate medical course, most of them denied having had any training or having had updates in their hospital setting. This situation shows the need to develop activities that raise awareness to the importance of spreading the culture of patient safety, as well as to mandatorily train doctors on the protocol use. Such initiatives would support the global dissemination of the Patient Safety agenda contributing to spreading the Brazilian Health Ministry/ ANVISA adapted version of the WHO Global Challenges (Surgery Safe Save Lives) ${ }^{1}$. It is worth mentioning that compliance with the WHO Patient Safety Curriculum Guide ensures for example the importance of laterality. Thus, with the correct implementation of the protocol, as well as its constant monitoring in hospitals and medical courses, there will be a continuous reduction of related surgical adverse events, ensuring patient safety ${ }^{9}$.

An American study on patient safety, carried out in 2018, revealed that human failures are accountable for $55 \%$ of surgical adverse events. The researchers evaluated 5,365 surgical procedures performed in three hospitals. The included surgical specialties were general surgery, trauma, oncology, cardiothoracic, vascular, and abdominal transplants. One hundred eighty-eight adverse events were found, most of which (55\%) occurred during surgery, another $27 \%$ occurred in the postoperative, and $8 \%$ in the preoperative period. $4 \%$ of the adverse events had errors in more than one of the check list stages. The researchers classified errors into five categories: Planning and problem-solving errors (when reaching a diagnosis or recommending treatment); Execution errors (when performing a procedure, making a prescription or reading test results); Errors for rule violation (conscious decision to ignore or circumvent safe practices); Communication errors (by omission, misinterpretation of information or presumption of knowledge); Failures in teamwork (problems in the allocation of roles, lack of leadership). The authors concluded that most errors occurred in the execution phase (51\%). Failures in planning and problem 
solving (29\%) ranked second. Communication problems ranked third $(12 \%)$, while failures caused by problems in teamwork ( $5 \%)$ and by rule violation (3\%) were the least frequent. According to one of the authors, Todd Rosengart, "Many things are happening at once in the operating room, and there is much pressure, which creates many opportunities to make a mistake"11.

When questioning the surgical procedure itself, surgeons were asked if there were any problems during the operation due to uncalibrated equipment and or lack of essential materials. The main problems were as follow: electric scalpel, the electrocautery, the curette, the surgical lighting, video material, and mechanical ventilator. Regarding the lack of materials, the main problems were the fenestrated fields, forceps, arthroscopic material, and surgical stapler. In those cases, despite the lack of materials and equipment failure, they were notified before the surgical procedure had started. Thus, errors occurred but did not impact patient safety, only generating extra costs to the hospitals.

Although the majority of the participants confirmed adequate surgical material sterilization, a considerable percentage mentioned episodes in which this was an issue. For example, the most reported adverse events were bones in drills, wet surgical material boxes, and the presence of pens inside of the boxes. In this context, despite the inadequate sterilization, the adverse event did not compromise the surgical procedure, since surgeons reported the mistake, not harming the patient's safety. It is crucial to standardize the Safe Surgery Protocol both in hospitals and in medical schools improving awareness, and thus compliance among surgeons leading to reduced risks of adverse events ${ }^{12}$.

During the pre and intraoperative periods, the surgeon may face several adversities, such as: lack of workups, lack of evaluation and control of comorbidities, lack or failure of equipment, and lack of materials. However, our data showed that most of these adverse events did not happen when the patient had already been anesthetized.

Regarding the patients, most of them knew the procedure they were undergoing, but they were not aware about the duration of the procedure as well as the type of anesthesia. Also, communication failure became \evident when patients reported not having been introduced to the surgical team. This result is in accordance with a recent
American study on the incidence of adverse events. The researchers observed that the lack of communication was the third problem that most impacts patient safety. The first problem was the execution process, and the second was planning and problem-solving ${ }^{11}$.

Regarding the surgical site (laterality), antibiotic prophylaxis, and blood reservation, a failure to comply with such measures was observed. "The surgical site identification must be performed by a physician who is a member of the surgical team before referring the patient to the surgical procedure place. Whenever possible, the identification should be made with the patient conscious and awake, confirming the location of the intervention [...]. The nurse must check whether the surgeon demarcated the surgical site on the patient's body in those cases where the surgical procedure involves laterality, multiple structures, or multiple levels" ${ }^{5}$. Antibiotic prophylaxis has been well documented by the Hospital Sírio Libânes protocol (2015) that indicates strategies to be adopted in all the operation and considering the anatomic regions in order to avoid infections and ensure patient safety ${ }^{13}$. However, in some cases, antibiotic prophylaxis was not necessary. Regarding the observed failure in blood reservations, it should be disclosed that in the current study most of the procedure were of low complexity, which might explain why for some patients this was not performed.

\section{CONCLUSION}

Our data showed safe surgery checklists in the two hospitals are a routine. However, there are significant flaws in all the different stages of its application. We observed an indirect association between time since physicians' graduation and knowledge about the safety protocol, which demonstrates the recent implementation of this concept in the regional medical courses. Nonetheless, most of the younger physicians who were acquainted with the safety protocol reported not having undergone further training in their current practice, which highlights the need to promote hospital training programs. The minority of the adverse events occurred with patients already anesthetized, and the majority was related to the lack of materials or non-calibrated equipment, such as video surgery equipment or the lack of adequate sterilization of surgical materials. Most patients 
are not informed about the type of anesthesia they will use, and the surgical procedure duration. This impacts on the adequate provided care to the patient and to the family members. Also, patients reported not having been introduced to the surgical team. All these aspects highlight the need for prior marking of the surgical site, ensuring laterality, as well as the use of antibiotic prophylaxis and blood reservation. With the correction of such errors, and the proper implementation the protocol steps, there will be a continuous reduction of adverse events associated to the surgical procedure, ensuring patient safety.

\title{
R E S U M O
}

\begin{abstract}
Objetivo: identificar o conhecimento e a taxa de adesão ao Protocolo de Cirurgia Segura pelos cirurgiões, assim como a incidência de eventos adversos relacionados à operação, além do conhecimento dos pacientes sobre o protocolo. Métodos: estudo transversal, prospectivo com caráter quantitativo. Para a coleta de dados, foi elaborado, pelos autores, um instrumento que coletou o perfil sócio gráfico de sessenta e oito cirurgiões e residentes, o conhecimento e a adesão destes ao protocolo de cirurgia segura. Oitenta e dois pacientes foram entrevistados, e o ambiente de cirurgia avaliado. Os dados foram analisados de maneira descritiva e teste Razão das Chances com Índice de Confiança (IC) de 95\%. Resultados: parte dos cirurgiões demonstraram que apesar do contato com o protocolo durante o período de formação, houve deficiência à adesão, ocasionando eventos adversos como o uso de equipamentos não calibrados ou presença de corpos estranhos nos equipamentos, como brocas e canetas. Além disso, foi constatado que em pacientes já anestesiados, as falhas foram percebidas e reparadas antes do começo do procedimento. No caso dos pacientes, estes demonstraram conhecimento quanto à cirurgia que iriam realizar, porém não sabiam a duração da mesma ou tinham sido introduzidos à equipe cirúrgica. Conclusão: houve falhas na dinâmica e na adesão de algumas etapas do protocolo, prejudicando a lateralidade no processo e a segurança do paciente.
\end{abstract}

Palavras chave: Segurança do Paciente. Protocolos. Cirurgia Geral. Ortopedia. Cirurgia Plástica.

\section{REFERENCES}

1. Correia MITD, Tomasich FDS, Castro Filho HF, Portari Filho PE, Colleoni Neto R. Segurança e qualidade em cirurgia: a percepção de cirurgiões no Brasil. Rev Col Bras Cir. 2019:46(4):e2146.

2. Panesar SS, Shaerf DA, Mann BS, Malik AK. Patient safety in orthopaedics: state of the art. J Bone Joint Surg Br. 2012;94(12):1595-7.

3. Weiser TG, Regenbogen SE, Thompson KD, Haynes $A B$, Lipsitz SR, Berry WR, et al. An estimation of the global volume of surgery: a modelling strategy based on available data. Lancet. 2008;372(9633):139-44.

4. Panesar SS, Noble DJ, Mirza SB, Patel B, Mann B, Emerton $\mathrm{M}$,et al. Can the surgical checklist reduce the risk of wrong site surgery in orthopaedics? -- Can the checklist help? Supporting evidence from analysis of a national patient incidente reporting system J Orthop Surg Res. 2011;6:18.

5. Segundo desafio global para a segurança do paciente: Cirurgias seguras salvam vidas (orientações para cirurgia segura da OMS) / Organização Mundial da Saúde. Rio de Janeiro: Organização Pan-Americana da Saúde; Ministério da Saúde; Agência Nacional de Vigilância Sanitária; 2009.
6. Anvisa. Agência Nacional de Vigilância Sanitária. Manual Cirurgias Seguras Salvam Vidas. Aliança Mundial para Segurança do Paciente.[publicação online]; 2008 [Acesso em: 26 set. 18]. Disponível em: http://portal.anvisa.gov.br/wps/portal/anvisa/ home $\% 20$

7. Kohn LT, Corrigan JM, Donaldson MS, editors. To err is human: building a safer health system. Washington: National Academy Press; 2000.

8. Scheffer M, Cassenote A, Guilloux AGA, Biancarelli A, Miotto BA, Mainardi GM. Demografia Médica no Brasil 2018. São Paulo: Departamento de Medicina Preventiva da Faculdade de Medicina da USP; Conselho Regional de Medicina do Estado de São Paulo; Conselho Federal de Medicina; 2018. p. 286.

9. Ministério da Saúde (BR). Portaria n. 529, de 1 de abril de 2013. Institui o Programa Nacional de Segurança do Paciente (PNSP) [Internet]. Diário Oficial da República Federativa do Brasil. 4 Abr 2013 [acesso 2019 Ago 26]. Disponível em: https://www20.anvisa. gov.br/segurancadopaciente/index.php/legislacao/ item/portaria-529

10. Ministério da Saúde (BR). Fundação Oswaldo Cruz (Fiocruz). Agência Nacional de Vigilância Sanitária (ANVISA). Documento de referência para o Programa 
Nacional de Segurança do Paciente [Internet]. Brasília

(DF): Ministério da Saúde; 2014 [acesso 2019 Ago

26]. Disponível em: http://bvsms.saude.gov.br/bvs/ publicacoes/documento_referencia_programa_ nacional_seguranca.pdf

11. SuliburkJW,BuckQM, PirkoCJ, MassarwehNN, Barshes $\mathrm{NR}$, Singh $\mathrm{H}$, et al. Analysis of human performance deficiencies associated with surgical adverse events.

Received in: 12/01/2019

Accepted for publication: 12/27/2019

Conflict of interest: no.

Funding source: none.
JAMA Netw Open. 2019;2(7):e198067.

12. Purim KSM, Gonçalves CG, Binotto L, Groth AK, Aranha Júnior AA, Chibata $M$, et al. Checklist de segurança no ensino de cirurgia ambulatorial. Rev Col Bras Cir. 2019;46(3):e20192197.

13. Protocolo de antibioticoprofilaxia no paciente cirúrgico: atualização 2015. São Paulo: Hospital SírioLibanês; 2015.

\section{Mailing address:}

Pedro Henrique Alves Silva

E-mail: phalvess21@gmail.com

Murilo Baracat Cortese Conde

E-mail: murilo.conde@gmail.com

(c) (i) 